\title{
A Lower Cambrian brachiopod from the Harlech Dome
}

(Plate 1)

SIR - The discovery of some poorly preserved lingulids in the uppermost part of the Llanbedr Slates (Lower Cambrian) provides some useful biostratigraphical evidence tending to corroborate the otherwise unsubstantiated report of inarticulates ('similar to Kutorgina') by Fearnsides (1910) in contemporary beds near Harlech Castle (Matley \& Wilson, 1946, p. 11).

Specimens recovered by one of us (C. J. W) in situ from quarry exposures ( $\mathrm{SH} 62$ 678242) N of Llyn Cwm Mynach (see Fig. 1) occur parallel to regional cleavage planes $\left(155^{\circ} / 43^{\circ} \mathrm{W}\right)$ in the slates; this orientation is subparallel to bedding planes (e.g. $160^{\circ} / 37^{\circ} \mathrm{W}$ ) in the overlying Rhinog Grit immediately to the $W$.

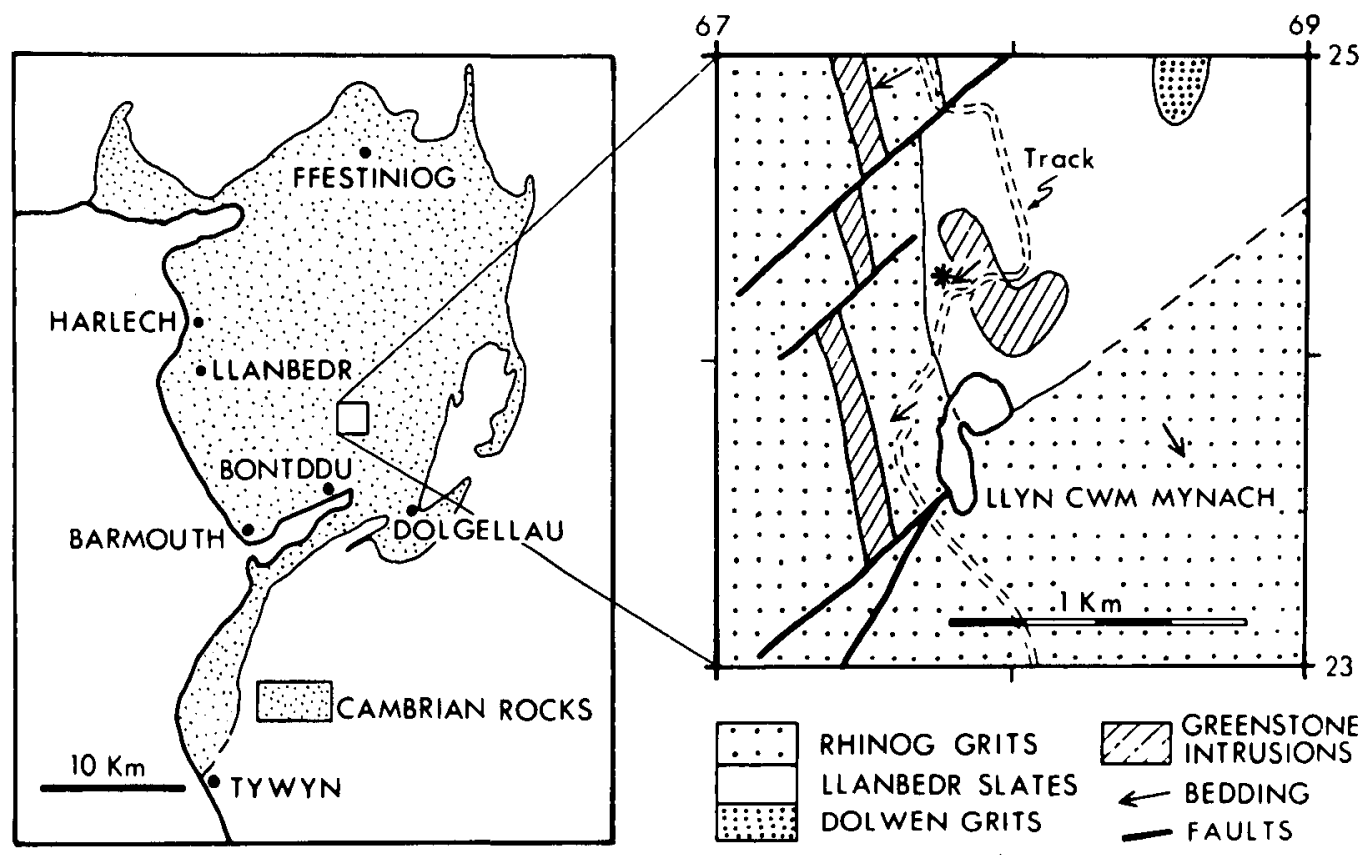

Figure 1. Map showing location of fossiliferous locality (marked by asterisk) in the Llanbedr Slates in relation to Cambrian outcrops of the Harlech Dome region. Geology of the area around Llyn Cwm Mynach modified after Matley \& Wilson (1946). The 'Greenstone intrusions ' have been referred to by Rushton (1974, p. 59) as 'sills... of micrographic hornblende-diorite porphyry'.

The two figured specimens, IA (Hunterian Museum no. L. $10881 \mathrm{a}, \mathrm{b}$ ) and $1 \mathrm{~B}$ (H.M. no. L. 10882a, b) both have counterparts and measure (length:width) $16: 8 \mathrm{~mm}$ and $14: 6 \mathrm{~mm}$ respectively; a third unfigured specimen (H.M. no. L. 10883) with no counterpart measures $12: 7 \mathrm{~mm}$. The largest, most complete and only slightly disarticulated specimen (shown in Plate 1 A) consists of severely altered ?chloritic material about 0-1 $\mathrm{mm}$ in thickness which composes the 'upper' valve and overlaps the impression of an underlying 'lower' valve. Where visible shell material is absent, as at the valve margins, it has evidently become fused with the rock imparting it a creamy-green colour and leaving a clear outline of the shell. Irregularly developed fine lines are interpreted as remnant growth lines.

Although the measurements indicate broadly similar length: width ratios $(43-58 \%$ as wide as long; mean $50 \%$ ) which may approximate to the original size and shape of the specimens the cleaved nature of the rock implies at least some degree of distortion. No inference concerning the orientation of the specimens at time of burial is therefore possible. The subfamilial taxonomic affinity of these specimens is uncertain; consideration of the morphological features described here only permits the material to be tentatively assigned to the Lingulidae. 
Current stratigraphical evidence (Cowie, Rushton \& Stubblefield, 1972, pl. 1), which places the Llanbedr (and Llanberis) Slates in the Lower Cambrian, suggests that the forms described here are contemporaneous with the oldest faunas known from North Wales (i.e. those originally recorded by Woodward (1888) and Fearnsides (1910) from near Bangor and Harlech respectively). The former, well-known Pseudatops viola (Woodward) fauna from the uppermost part of the Llanberis Slates, like the Harlech Castle and Llyn Cwm Mynach inarticulate faunas from the uppermost Llanbedr Slates, notably occur at horizons associated with the terminal stages of a widespread phase of argillaceous deposition. However, although the occurrence of fossils at broadly contemporaneous horizons in three separate localities is noteworthy, the distinct differences between each faunal record, together with the paucity of material from the two Harlech Dome localities, currently renders them of little or no value for correlation in North Wales.

Acknowledgements to Professor A. Williams for examining the material; to both him and Professor T. N. George for reading the initial manuscript; and to N.E.R.C. for the provision of research grants.

\section{References}

Cowie, J. W., Rushton, A. W. A. \& Stubblefield, C. J. 1972. A correlation of Cambrian Rocks in the British Isles. Geol. Soc. Lond. Spec. Rep. no. 2, pp. 1-42.

Fearnsides, W. G. 1910. North and Central Wales. Geology in the Field 4, 786-825. London: Geol. Assoc. Matley, C. A. \& Wilson, T. S. 1946. The Harlech Dome, north of the Barmouth Estuary. Q. Jl geol. Soc. Lond. 102, 2-40.

Rushton, A. W. A. 1974. The Cambrian of Wales and England. In Lower Palaeozoic Rocks of the World (ed. C. H. Holland). Vol. 2. Cambrian of the British Isles, Norden and Spitsbergen, pp. 43-121. London: Wiley.

Woodward, H. B. 1888. On the discovery of trilobites in the Upper green Cambrian Slates of the Penrhyn Quarries, Bethesda, near Bangor, North Wales. Q. Jl geol. Soc. Lond. 44, 74-8.

Department of Geology

M. G. LOCKLEY \& C. J. WILCOX

University of Glasgow

Lilybank Gardens

Glasgow G12 8QQ

Scotland

14 July 1978

\section{EXPLANATION OF PLATES}

Plate 1(A). Slightly disarticulated pair of lingulid valves (L. 10881a) showing broken shell material $(\times 3)$ posterior of valves to top of plate.

Plate l(B). Single lingulid valve (L. 10882a) on cleavage plane ( $\times 4.5)$, orientation uncertain. 
Geol. Mag. Vol. 116, 1979, Lockley \& Wilcox, Plate 1, facing page 64.
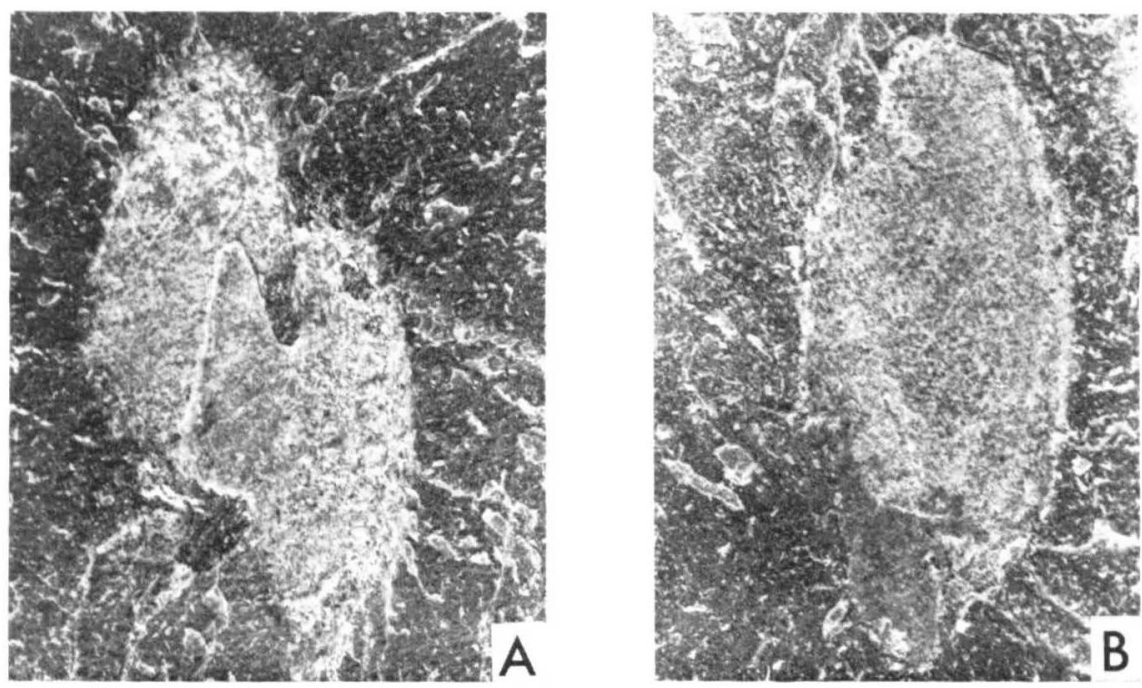

Plate 1. A Lower Cambrian brachiopod from the Harlech Dome. 